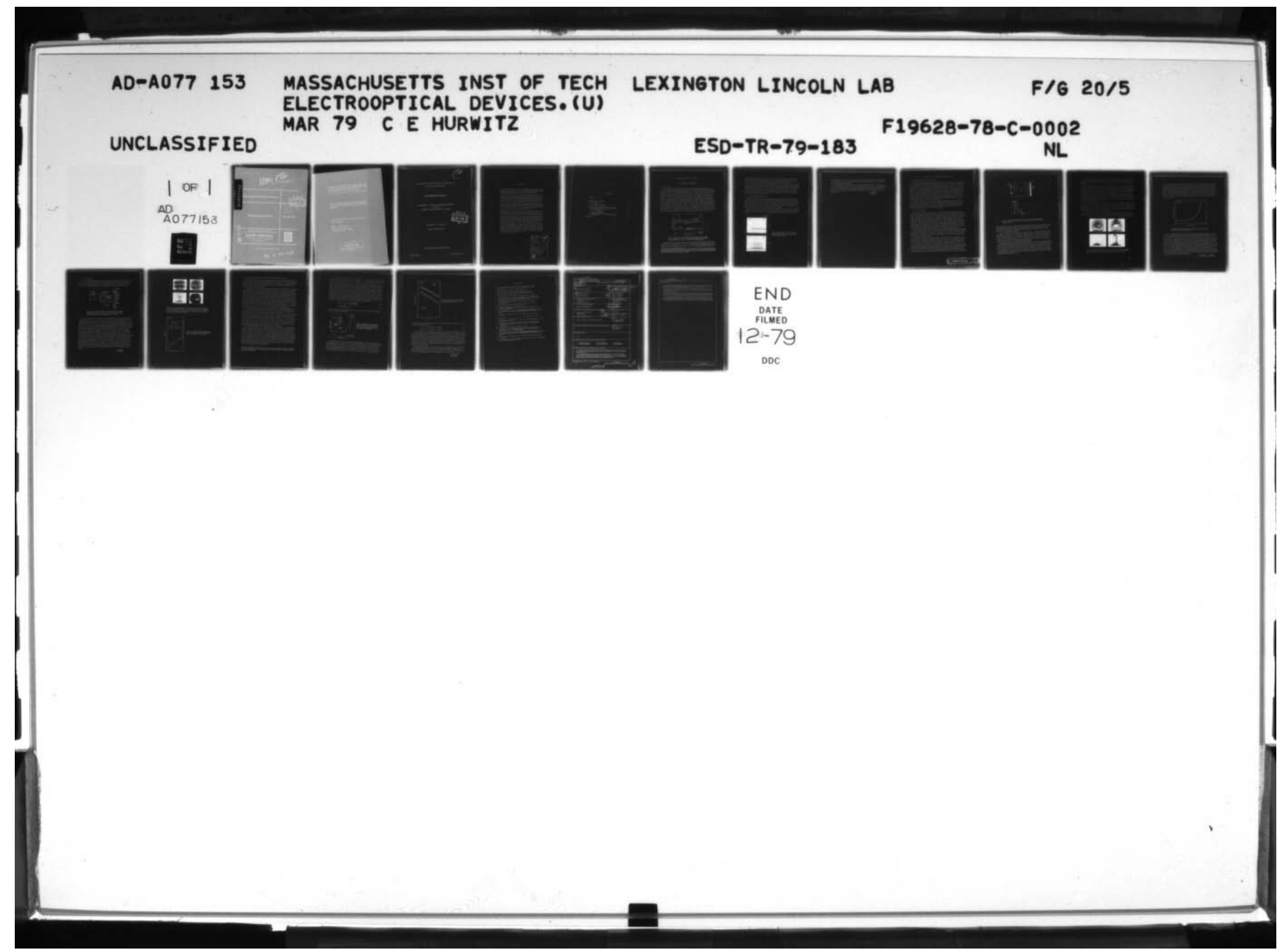




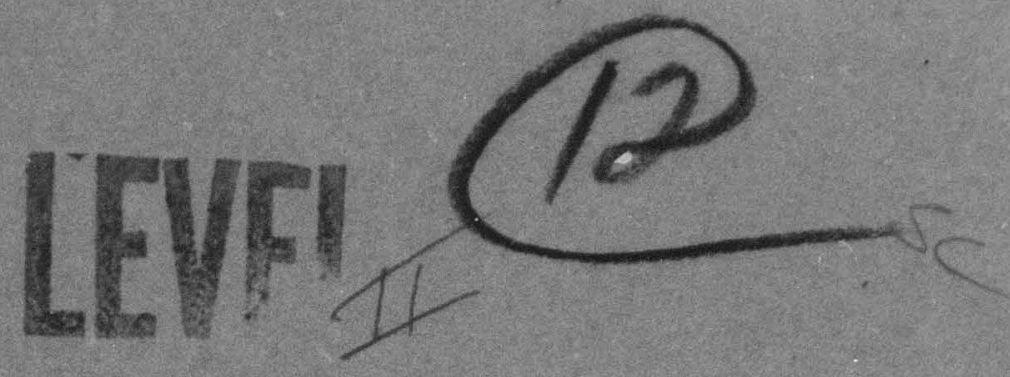

๑)

A. 69.091

2อ

I

ro

N Semiannual Technical Summary

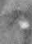

Electrooptical Devices

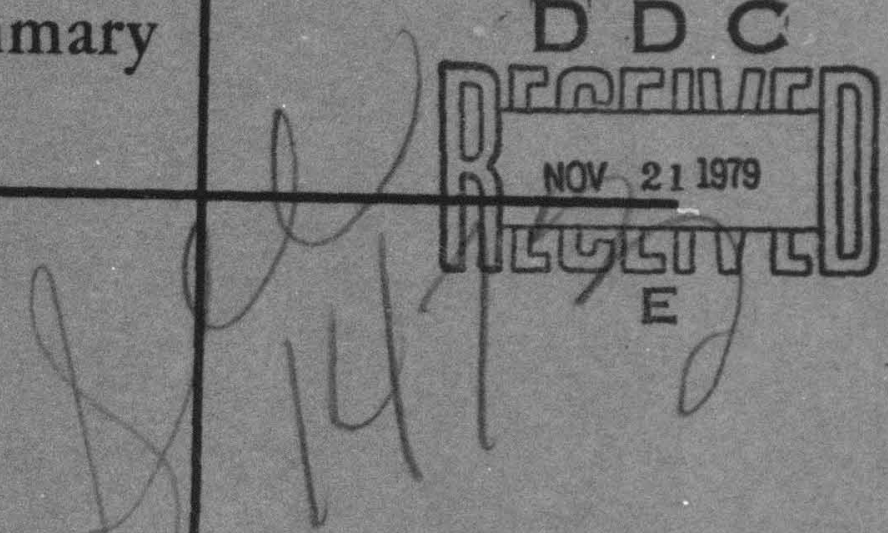

0

$<$

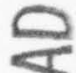

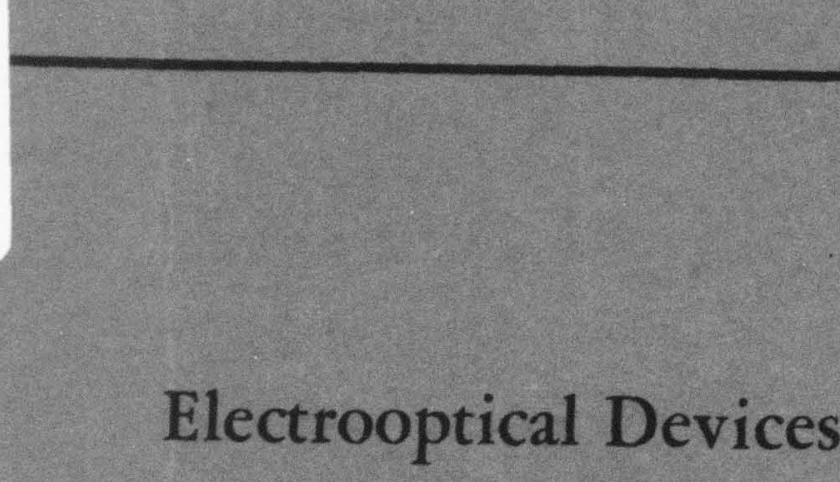

31 March 1979

Prepared for the Department of the Air Force

under Electronic Systems Division Contract F19628-78-C-0002 by

3 感

Lincoln Laboratory

MASSACHUSETTS INSTITUTE OF TECHNOLOGY

LF:Xington, Massachusetts

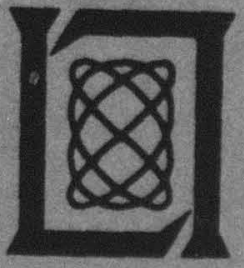

Approved for public release; distribution unlimited.

$$
791120 \cdot 149
$$


The work reported in this documcat was performed at Lincoln Laboratory, à center

this support was provided by the ratisfy needs of U.S. Government agencies. This report nay be reproduced to sath

The views and conclusioas contained in this document are those of the The views and conclusioas contained in this document are those
contractor and should not be interpreted as necessarily representing the
official policies, either expressed of Implied, of the United States Government.

This technical report has been reviewed and is approved for publication.

\section{FOR THE COMMANDER}

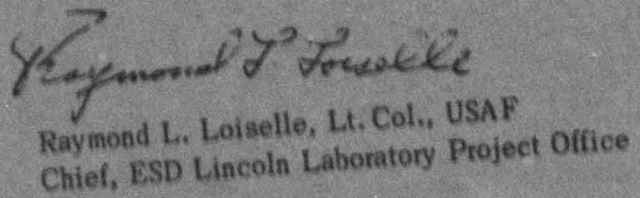

Chief, ESD Lincoln Laboratory Proje

\section{Non-Lincoln Recipients \\ PLEASE DO NOT RETURN}

Permission is given to destroy this document when it is no longer needed. 


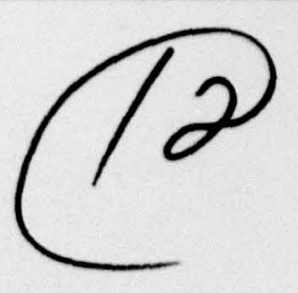

MASSACHUSETTS INSTITUTE OF TECHNOLOGY

LINCOLN LABORATORY

\section{ELECTROOPTICAL DEVICES}

SEMIANNUAL TECHNICAL SUMMARY REPORT

TO THE

ROME AIR DEVELOPMENT CENTER

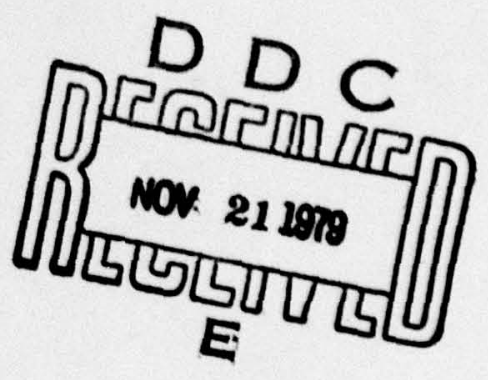

1 OCTOBER 1978 - 31 MARCH 1979

ISSUED 27 SEPTEMBER 1979

Approved for public release; distribution unlimited. 
This report covers work carried out with support of the Department of the Air Force during the period 1 October 1978 through 31 March 1979. -A part of this support was provided by the Rome Air Development Center.

The current objectives of the electrooptical device program are: (1) to perform life tests on GaInAs P/InP double-heterostructure (DH) diode lasers operating in the $1.0-$ to $1.3-\mu \mathrm{m}$ wavelength region and analyze the degradation mechanisms, and (2) to fabricate and study avalanche photodiodes of similar composition GaInAs P operating in the same wavelength region.

Two stripe-geometry GaInAsP/InP lasers have now operated CW for nearly 8,000 and $10,000 \mathrm{hr}$, respectively, at room temperature with no indication of failure. Projected lifetime for $\mathrm{CW}$ operation at room temperature, based on accelerated aging at $50^{\circ} \mathrm{C}$, now exceeds $15,000 \mathrm{hr}$.

Self-pulsations, similar to those observed in GaAs/AlGaAs lasers, have been noted in some GaInAsP/InP lasers. Pulse widths less than $100 \mathrm{psec}$ and repetition rates from $100 \mathrm{MHz}$ to more than $1 \mathrm{GHz}$ have been measured.

Guarded avalanche photodiodes of both the $p^{+}-n$ and $n^{+-} p$ configurations have been fabricated in InP using a double ion implantation to form a planar junction with a central uniform high-field region. The devices were free from edge breakdown and showed uniform avalanche gains as high as twenty.

The ionization coefficients of electrons and holes in InP have been determined from photomultiplication measurements on abrupt-junction, lowleakage, $\mathrm{np}^{+} \mathrm{InP}$ avalanche photodiodes. The ionization rate of holes $(\beta)$ was found to be greater than that for electrons $(\alpha)$, the ratio varying with peak electric field $\left(\mathrm{E}_{\mathrm{m}}\right)$ from $\beta / \alpha=3.8$ at $\mathrm{E}_{\mathrm{m}}=4.85 \times 10^{5} \mathrm{~V}-\mathrm{cm}^{-1}$ to $\beta / \alpha=2.7$ at $\mathrm{E}_{\mathrm{m}}=6.37 \times 10^{5} \mathrm{~V}-\mathrm{cm}^{-1}$.

\begin{tabular}{|c|c|}
\hline \multicolumn{2}{|c|}{ Accession For } \\
\hline $\begin{array}{l}\text { NTIS } \\
\text { DDC TAI } \\
\text { Unannor } \\
\text { Justif }\end{array}$ & $\begin{array}{l}\text { GRARI } \\
\text { Bunced } \\
\text { ication }\end{array}$ \\
\hline $\mathrm{By}_{\ldots}$ & \\
\hline Distri & bution/ \\
\hline Avail & ability Codes \\
\hline $\mathscr{N}$ & $\begin{array}{l}\text { Avall and/or } \\
\text { special }\end{array}$ \\
\hline
\end{tabular}


1. GalnAsP/InP DH LASERS

A. Life Tests

B. Self-Sustained Pulsations

II. GainAsP AND InP AVALANCHE PHOTCDIODES

A. Planar Guarded InP Structures

1. $p^{+}-n$ Configuration

2. $n^{+}-p$ Configuration

B. Ionization Coefficients of Electrons and Holes in (100)- InP 


\section{A. LIFE TESTS}

As we reported previously, ${ }^{1,2}$ improvements in the threshold-current density and in the mounting techniques of the GaInAsP/InP lasers have led to much greater stability in the thermal impedance of devices as a function of $\mathrm{CW}$ operating time. Gradual increase of the thermal impedance has been shown to be the dominant mode of short- to medium-term degradation. Three long-lived lasers remain on life test at room temperature. The longest lived is approaching $10,000 \mathrm{hr}$, but its output is slowly declining. The next has been operating for approximately $9,000 \mathrm{hr}$. Unstable output with operating time has been occasionally observed, although the device is currently operating at its original output and shows no further change. Both these devices have large threshold-current densities $\left(>6 \mathrm{kA} / \mathrm{cm}^{2}\right)$ and are subject to unstable heat-sinking as described earlier. ${ }^{2}$ The third device, however, is from a relatively low-threshold wafer $\left(\mathrm{J}_{\mathrm{T}}=2.9 \mathrm{kA} / \mathrm{cm}^{2}\right)$ and has now reached $7,800 \mathrm{hr}$ with no change in output. Figure $\mathrm{I}-1$ shows the threshold current vs $\mathrm{CW}$ operating time for this device compared with an earlier device with a higher threshold. It is important to note that there was no preselection of this device other than for its low threshold and, further, that it is running in air with no protective facet coating.

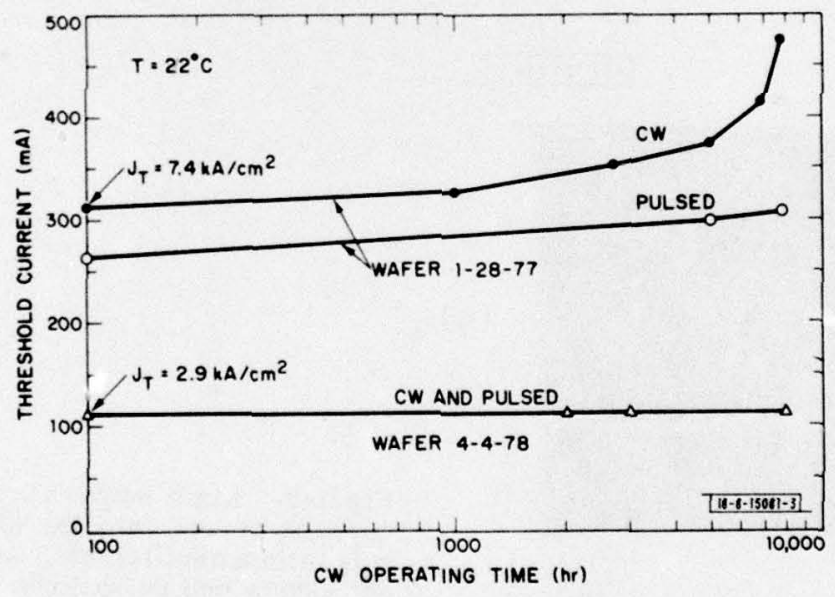

Fig. I-1. Dependence of threshold-current density on CW operating time of two devices. Device with larger current density shows gradual degradation due, in part, to increased thermal resistance.

Two other devices, specially processed to stabilize their thermal impedances, were operated $\mathrm{CW}$ at $50^{\circ} \mathrm{C}$ for approximately $1,200 \mathrm{hr}$. If we assume that the degradation process can be described by an activation energy on the order of $0.7 \mathrm{eV}^{\dagger}$ the projected room-temperature life

The degradation of GaAs/AlGaAs DH lasers has been found by many workers to be describable by processes with activation energies in the range of 0.7 to $1.0 \mathrm{eV}$. Assuming that the long-term degradation of the GaInAsP/InP lasers results from similar processes, an activation energy of $0.7 \mathrm{eV}$ would probably be a conservative estimate. 
of these devices would be approximately $15,000 \mathrm{hr}$. No specific degradation mechanisms for these devices were established, as we believe that a much larger number of devices need to be observed to establish statistically and physically meaningful results at this point.

In summary, long operating life at room temperature can be achieved without any facet passivation, provided the previously described ${ }^{1}$ initial cleaning is performed. Instability of thermal heat-sinking can be largely eliminated as well, and room-temperature lifetimes on the order of $10,000 \mathrm{hr}$ appear to be easily achieved, particularly for low-threshold devices. Very longterm degradation mechanisms most probably also exist; however, their study would require a much more extensive program of accelerated aging of large numbers of devices, an endeavor which is beyond the scope of this program.

\section{B. SELF-SUSTAINED PULSATIONS}

Figure 1-2(a) shows the light output signal vs time of a GaInAsP/InP laser, as detected in a Ge avalanche photodiode, following excitation of the laser with a step of current (70-nsec duration). This device shows a normal damped relaxation oscillation. In Fig. I-2(b), the output of another GalnAsP/InP device is shown in which the relaxation oscillations are not damped. This phenomenon has been termed "self-sustained pulsation," and is subject of considerable current interest and controversy in studies of III-V semiconductor lasers. ${ }^{3}$

Thus far, we have observed this phenomenon in a number of devices from our lowest threshold wafers. If understood and controlled, the self-sustained oscillations could be useful in some applications. The repetition rate of the pulses can be varied with drive current from a few
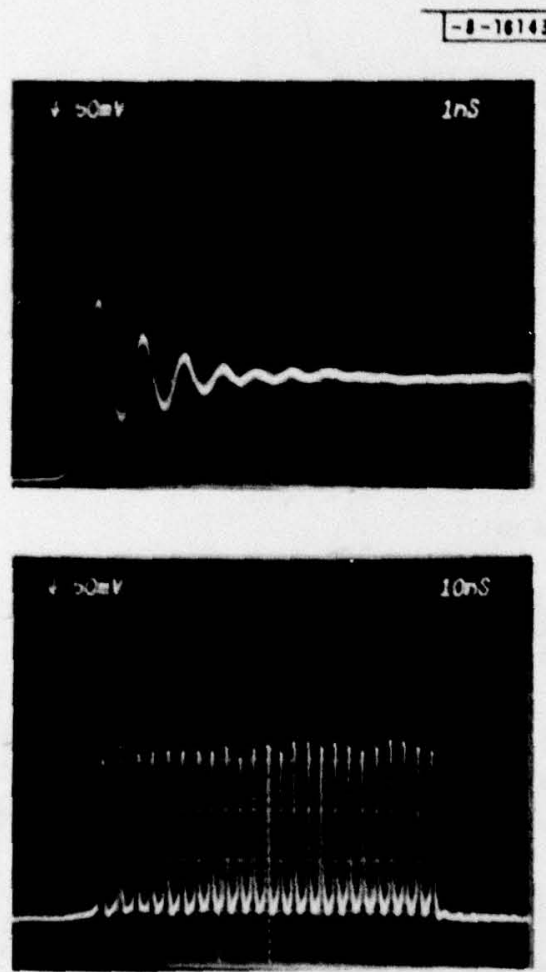

(a)

(b)

Fig. 1-2, Light output vs time with $70-$ nsec current pulses into (a) diode with damped relaxation oscillations, and (b) diode with self-sustained pulsations. 
hundred megahertz to $1 \mathrm{GHz}$ or more, and the pulse width can be quite small. On one device we have measured a value for the pulse width of 100 psec, an upper limit imposed by the response time of the measurement apparatus.

For most applications, such as transmitters for optical communications, it is important that these pulsations be eliminated, and it is particularly important to discover if initially stable devices become "self-pulsers" during aging, as has been observed in AlGaAs/GaAs lasers. 2 So far, we have not observed self-pulsations induced by aging, but we are continuing to study this phenomenon.

J. N. Walpole

J. J. Hsieh

T. A. Lind 


\section{GaInAsP AND InP AVALANCHE PHOTODIODES}

\section{A. PIANAR GUARDED InP STRUCTURES}

Guarded avalanche photodiodes have been fabricated in InP by using a double ion implantation to form a planar junction with a uniform central high-field region. The basic device configuration, which is similar in structure to that of Si reach-through diodes, consists of a shallow implanted circular $p-n$ junction and a deeper implanted layer, concentric with the first, but smaller in diameter. The second implantation produces the same conductivity type as the starting material and is used to controllably increase the carrier concentration in the central portion of the diode, so that the breakdown voltage in this region is less than that at the diode perimeter. Both $\mathrm{p}^{+}-\mathrm{n}$ and $\mathrm{n}^{+}-\mathrm{p}$ diodes have been investigated. For the $\mathrm{p}^{+}-\mathrm{n}$ diodes, the $\mathrm{p}-\mathrm{n}$ junction and central high-concentration regions were formed by implanting $\mathrm{Be}$ and $\mathrm{Si}$, respectively, into epitaxially grown $n-I n P$. For the $n^{+}-p$ diodes, bulk p-type InP was implanted with Se and $B e$ to form the junction and high-field region, respectively.

In addition to the value of this structure in reducing effects of edge breakdown, it should also prove useful in optimizing the electric-field profile to maximize the avalanche gain and/or the carrier collection efficiency. Furthermore, our previous results indicate that the ionimplantation techniques employed here should be directly transferable to the GaInAsP system for photodiodes with response in the $1.0-$ to $1.6-\mu \mathrm{m}$ region.

1. $\mathrm{p}^{+}-\mathrm{n}$ Configuration

Figure II-1(a-b) illustrates schematically a cross section of a double-implanted, guarded InP $\mathrm{p}^{+}-\mathrm{n}$ junction diode. Viewed from the top, the $\mathrm{p}^{+}-$and $\mathrm{n}$-regions would appear as concentric circles. By appropriately selecting the carrier concentration $n$ and the thickness $t$ of the $n$-type region (in relation to the concentration in $\mathrm{n}^{-}$-region), the maximum electric field at breakdown in the central region can be made larger than the electric field at the edge of the $\mathrm{p}^{+}$-region.

Under this condition, avalanche breakdown will occur in the central portion of the diode and not at the edge. The minimum nt product necessary to prevent edge breakdown depends on both the concentration in the $n^{-}$-region and the shape of the $p^{+}-n^{-}$boundary at the periphery. For initial design purposes, the maximum field at the edge of an implanted $0.3-\mu m-$ deep $p-n$ junction due to field crowding was estimated to be about twice that in the flat portion of the junction. 4

The InP samples used in this work consisted of an unintentionally doped n-type epitaxial layer ( $\mathrm{n}^{-}$-region of Fig. II-1) with an electron concentration of 1 to $2 \times 10^{16} \mathrm{~cm}^{-3}$ grown by liquid-phase epitaxy on a (100)-oriented $n^{+}$-InP substrate. The thickness of the epilayer is not ciritcal, but was chosen to be greater than $6 \mu \mathrm{m}$ to prevent punch-through, which would somewhat negate the guarding properties of this structure.

To achieve the central $\mathrm{n}$-type region of $\mathrm{Fig}$. II-1, 400-keV Si${ }^{+}$ions were implanted into each sample through 6-mil-diam holes opened in a thick $(\sim 5-\mu \mathrm{m})$ photoresist implantation mask and a thin $\mathrm{SiO}_{2}$ layer. During the implantation, the samples were held at either room temperature or $170^{\circ} \mathrm{C}$. Due to uncertainties in junction edge effects, two different doses $\left(8 \times 10^{12}\right.$ or $1.5 \times$ $10^{13} \mathrm{~cm}^{-2}$ ) were tried. The lower dose was selected to result in both a peak electron concentration about ten times greater than the concentration in the epitaxial layer, and at breakdown a maximum electric field in the central region greater than twice that in the flat portion of the outer rim. This dose $\left(8 \times 10^{12} \mathrm{~cm}^{-2}\right)$ is higher than might at first be expected from simple charge considerations because (a) only about 80 percent of the implanted $\mathrm{Si}$ is expected to be electrically 


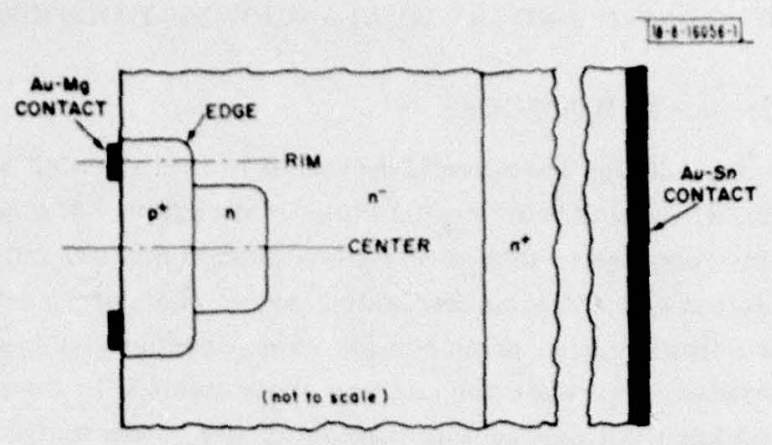

(a)

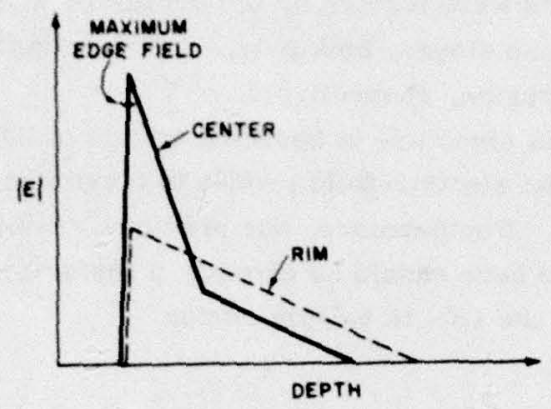

(b)

Fig. II-1. Schematic illustration of (a) cross section of a planar guarded InP $\mathrm{p}^{+}-\mathrm{n}$ junction diode, and (b) resulting idealized electric-field profile through device.

active (see below), and (b) the subsequent Be p-type implant (described below) partially overlaps the implanted Si profile, thus compensating a substantial fraction of the silicon. If all the implanted Si were electrically active and entirely deeper than the $p^{+}$-region, doses of $(2$ to 4$) \times$ $10^{12} \mathrm{~cm}^{-2}$ would probably be sufficient.

After the Si implant, 10-mil-diam holes concentric with the 6-mil-diam Si-implanted regions were opened in a new layer of thick photoresist and the thin $\mathrm{SiO}_{2}$. The samples were then implanted at room temperature with beryllium to produce the $p^{+}-$layer of Fig. II-1. The dose schedule used for the Be implant was $2 \times 10^{13} \mathrm{~cm}^{-2}$ at $40 \mathrm{keV}$ and $3 \times 10^{13} \mathrm{~cm}^{-2}$ at $30 \mathrm{keV}$, which should result in a maximum as-implanted Be concentration of $2.7 \times 10^{18} \mathrm{~cm}^{-3}$, a level at which no significant indiffusion of implanted Be has been observed. 5

Following implantation, the samples were annealed at $750^{\circ} \mathrm{C}$ for $10 \mathrm{~min}$. using a phosphosilicate glass (PSG) encapsulation procedure described previously. 5,7 From these earlier results, 5,7 about 60 percent of the implanted $B e$ and $>80$ percent of the implanted Si should be electrically active following this anneal. The $p-n$ junction depth is estimated to be about $0.30 \mu \mathrm{m}$ in the central region and $0.35 \mu \mathrm{m}$ in the outer rim. This difference in depth is due to the Gaussian falloff in the implanted Be profile and the difference in electron concentration between the Si-implanted region and the initial epitaxial layer. 
After annealing, the PSG was removed and a $1500-\mathrm{A} \mathrm{SiO}_{2}$ layer was deposited on the front surface of each sample. Holes $1.5-\mathrm{mil}$ in diameter were opened in the $\mathrm{SiO}_{2}$, and evaporated $\mathrm{Au}-\mathrm{Mg}$ contacts were made to the $\mathrm{p}^{+}$-regions. Electroplated Au-Sn was used to contact the $\mathrm{n}^{+}$ substrates.

For initial evaluation of these diodes, I-V characteristics were measured and scanned photoresponse measurements were performed using the 6328 line of a He-Ne laser. The laser spot size was nominally $6 \mu \mathrm{m}$ in diameter and the power was adjusted so that the unmultiplied photocurrent was $\leqslant 50 \mathrm{nA}$. Diodes on all the samples exhibited photoresponse gain in the central portion, but best results were obtained on the sample implanted at $170^{\circ} \mathrm{C}$ with $8 \times 10^{12} \mathrm{Si}_{\mathrm{cm}}^{-2}$. Since previous work has shown that less residual damage and higher activation of implanted $\mathrm{Si}$ can be achieved by performing the implant at elevated substrate temperatures, ${ }^{7}$ the improved performance for the higher implant temperature is not surprising. The lower of the two doses is apparently sufficient to prevent edge breakdown, and its use should result in less damage and less Zener-tunneling current flow.

The I-V characteristics of these diodes exhibit soft breakdown. Breakdown, arbitrarily defined as the voltage at which $10-\mu \mathrm{A}$ reverse current flows, occurs typically at $18 \pm 0.5 \mathrm{~V}$ reverse bias. The sources of the anomalous leakage currents which are causing the soft breakdown are now being investigated. When the causative factors are identified, methods to reduce the leakage will be developed and incorporated in the device fabrication procedures. This should result in substantial improvements in device characteristics.

Figures II-2(a) and (c) show the scanned photoresponse of a typical diode at a reverse bias of 2 and $18.2 \mathrm{~V}$, respectively. Figures $\mathrm{II}-2(\mathrm{~b})$ and $(\mathrm{d})$ consist of the horizontal scans of (a) and (c), respectively, superimposed so relative magnitudes are more easily discernible.

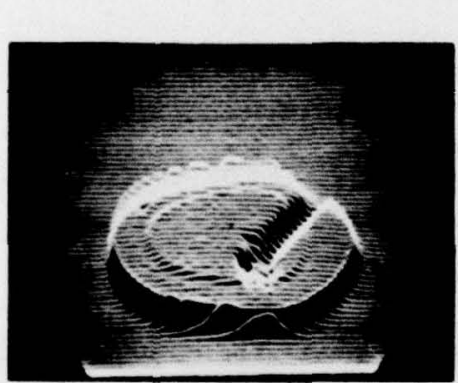

(a)

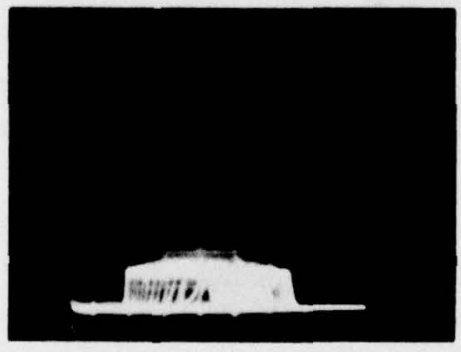

(c)

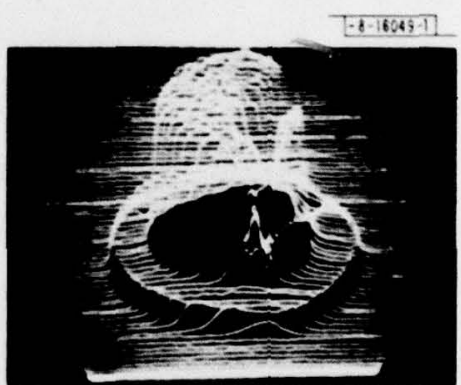

(b)

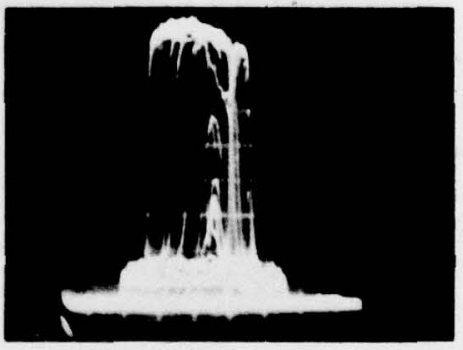

(d)

Fig. II-2. Photoresponse scans at $0.6328 \mu \mathrm{m}$ of a typical planar guarded InP diode: quasi-three-dimensional display at (a) $2 \mathrm{~V}$ and (c) $18.2 \mathrm{~V}$ reverse bias; two-dimensional display at (b) $2 \mathrm{~V}$ and (d) $18.2 \mathrm{~V}$ reverse bias. 
At $2 \mathrm{~V}$ reverse bias, the photoresponse is relatively flat. There is a slightly figher response at the edge due to a higher collection efficiency where the junction comes to the surface, as well as a slightly higher response in the central portion of the diode. The latter effect is probably due to the shallower junction depth expected in the central region, as discussed above. At $18.2 \mathrm{~V}$ reverse bias, the photoresponse in the central region is uniform and greater than 7 times that at $2 \mathrm{~V}$ reverse bias, while the photoresponse in the outer rim is essentially the same as observed at $2 \mathrm{~V}$. The depression in the photoresponse in the center is due to the $\mathrm{Au}-\mathrm{Mg}$ contact and the lead wire. The dark current of this particular diode is less than $0.1 \mathrm{nA}$ at $2 \mathrm{~V}$ and $10 \mu \mathrm{A}$ at $18.2 \mathrm{~V}$ reverse bias.

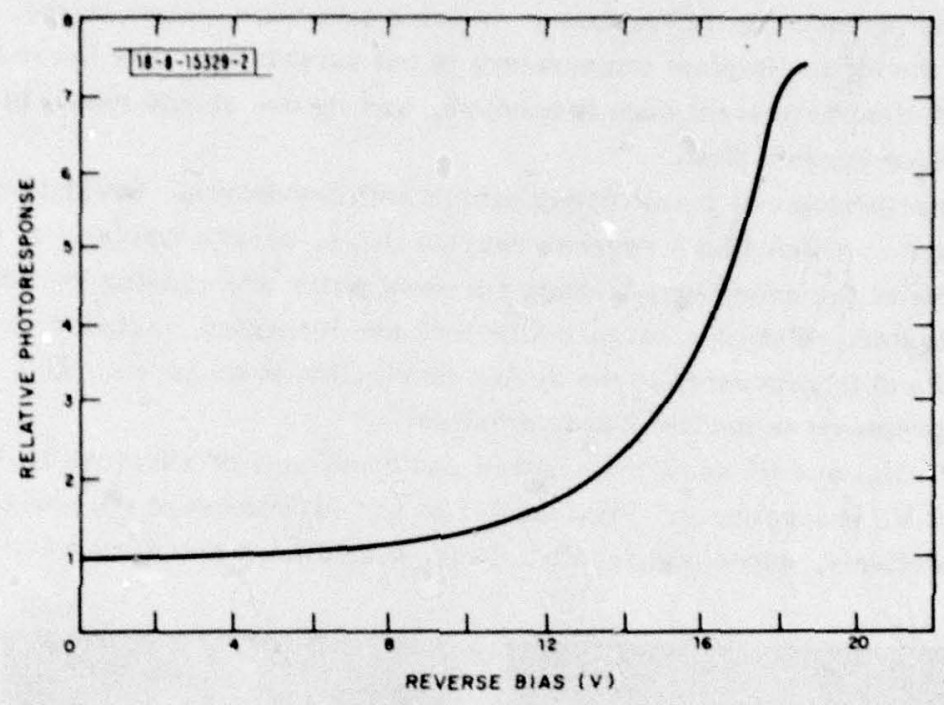

Fig. II-3. Relative photoresponse vs reverse bias of central portion of a typical InP diode with a 1-k $\Omega$ load.

When operating into a 1-k $\Omega$ load, several diodes showed photoresponse gains as high as 20. However, the central photoresponse of these devices peaked more typically at gains of 6 to 8 . This is illustrated in Fig. II-3 which shows the relative photoresponse of the central region vs reverse bias for a typical diode with a $1-\mathrm{k} \Omega$ load. Higher gains could be obtained by lowering the load resistance. Furthermore, as the photoresponse in the central portion began to saturate with increasing reverse bias, the photoresponse in the outer rim, which generally showed no photocurrent gain, began to decrease. If the ratio of central-to-outer-rim photoresponse is used to determine photocurrent gain in the central region, even typical diodes have gains greater than 20. These results indicate that, with increasing reverse bias, the external photoresponse becomes limited by the shunting effect of the diode's differential resistance, which decreases rapidly with increasing reverse bias due to the anomalous dark leakage current which is responsible for the soft breakdown. As mentioned earlier, studies of the sources of this large dark current and of methods for its reduction are in progress.

J. P. Donnelly

C. A. Armiento
V. Diadiuk S. H. Groves 
2. $\mathrm{n}^{+}-\mathrm{p}$ Configuration

The $n^{+}-p$ InP photodiodes shown schematically in Fig. II-4(a) are essentially similar in structure to the $\mathrm{p}^{+}-n$ devices described above. The starting material was bulk p-type InP with a net acceptor concentration of $1 \times 10^{16} \mathrm{~cm}^{-3}$. As detailed in Fig. II-4(b), implanted Se was used to form the $\mathrm{n}^{+}$-region and implanted Be produced the higher-concentration central p-region.

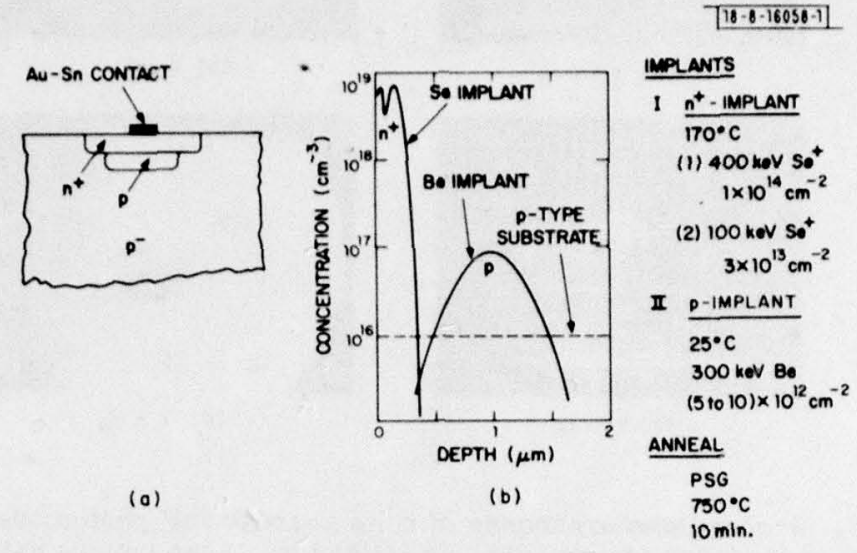

Fig. II-4. (a) Schematic illustration of cross section of a planar guarded InP $n^{+}-p$ junction diode. (b) Calculated profiles of ionimplanted $\mathrm{Be}$ and $\mathrm{Se}$ used to create structure in (a). Implant and anneal parameters actually employed are also shown.

The I-V characteristics of these diodes exhibited soft breakdown and relatively high leakage current $\left(50 \mu \mathrm{A}\right.$ at $\left.\mathrm{V}=1 / 2 \mathrm{~V}_{\mathrm{b}}\right)$. The devices were tested before and after removing a layer of pyrolytically deposited $\mathrm{SiO}_{2}$ that had been used as a contact mask during AuSn plating. With the exception of the observed photocurrent, which was an order-of-magnitude higher before removing the $\mathrm{SiO}_{2}$, the I-V characteristics remained basically unchanged, but there was a dramatic difference in the photoresponse scans taken with and without the $\mathrm{SiO}_{2}$ layer. The response to a scanned spot of 6328- $\AA$ radiation observed on samples still coated with $\mathrm{SiO}_{2}$ is shown in Figs. II-5(a) and (b) at zero bias and near breakdown. It is clear from Fig. II-5(b) that these are guarded structures, and, indeed, that breakdown occurs in the central portion at lower voltages than at the perimeter of the devices. However, the unexpected response observed outside of the implanted regions, where there is no (intentional) $p-n$ junction, points to the existence of an inverted n-type surface layer on the p-type substrate. This surface layer is probably responsible for at least some of the high leakage currents observed in these diodes. By removing the $\mathrm{SiO}_{2}$ layer, much of this anomalous response can be eliminated, indicating that the surface properties are strongly affected by the $\mathrm{SiO}_{2}$. However, in order to prevent the response at the edge where the p-n junction comes to the surface, it was necessary to coat the sample with $1300 \AA$ of $\mathrm{Si}_{3} \mathrm{~N}_{4}$. Figures II-5(c) and (d) show the uniform central response obtained when the sample surfaces were passivated in this manner. Typical photoresponse gains of 3 to 4 were observed in these diodes.

$$
\begin{aligned}
& \text { V. Diadiuk } \\
& \text { J. P. Donnelly } \\
& \text { G. W. Iseler }
\end{aligned}
$$




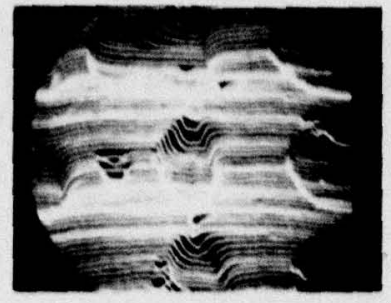

(a) $v=0$

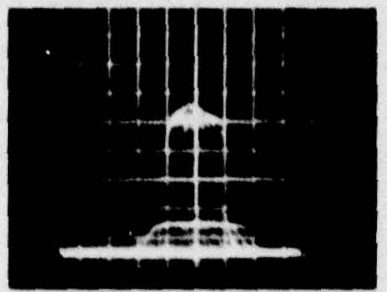

(c) $v=v_{8}$

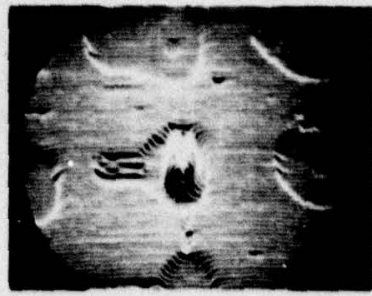

(b) $v=v_{B}$

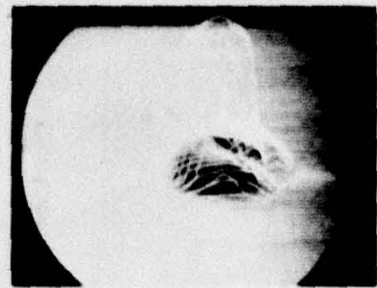

(d) $v=v_{B}$

Fig. 11-5. Scanned photoresponse of $n^{+}-p$ guarded InP photodiodes with two different passivation treatments. In (a) and (b), scan covers several adjacent SiOz-passivated devices, the center one being the device contacted: at zero bias (a) and near breakdown (b). Well-behaved single device in (c) and (d) was passivated with $\mathrm{Si}_{3} \mathrm{~N}_{4}$.

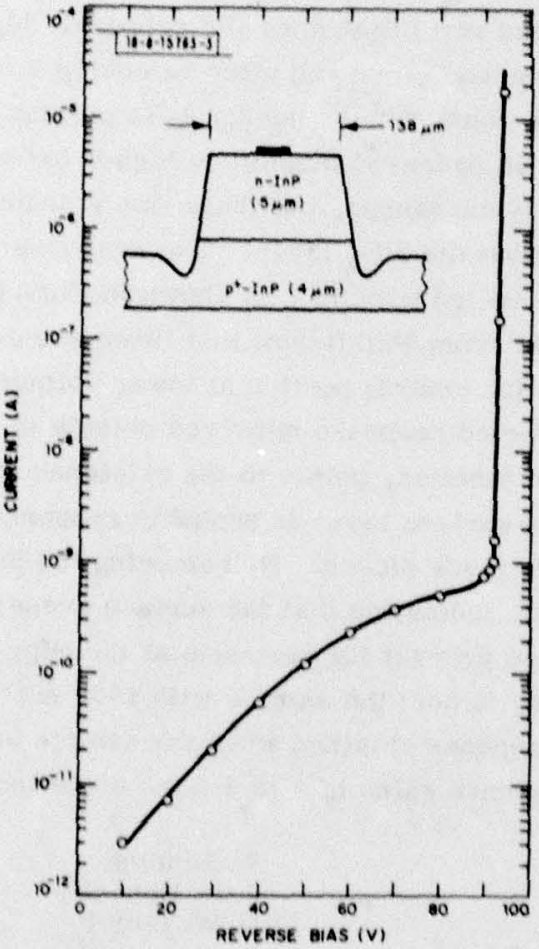

Fig. II-6. Current-voltage characteristics of a $138-\mu \mathrm{m}$-diam $n p^{+}-$InP avalanche photodiode. Inset shows device structure. 


\section{B. IONIZATION COEFFICIENTS OF ELECTRONS AND HOLES IN (100)-InP}

Knowledge of the ionization rates of electrons and holes in a semiconductor is highly important for the design of low-noise wide-bandwidth avalanche photodiodes 8,9 as well as high-efficiency low-noise IMPATT devices. ${ }^{10}$ From photomultiplication measurements on abrupt-junction, lowleakage $\mathrm{np}^{+}-$In $\mathrm{P}$ avalanche photodiodes, we have measured the ionization coefficients for the $\langle 100\rangle$ crystal direction in this material.

Unambiguous determination of the ionization rates from photomultiplication data on avalanche photodiodes requires two important experimental conditions. ${ }^{11}$ One is that pure-electron and pure-hole injection into the high-field region must be obtained in the same device. The second requirement is that the magnitude and variation of the junction electric field be known accurately. These two requirements are best met by use of an abrupt $\mathrm{p}-\mathrm{n}$ junction avalanche photodiode, where incident radiation is completely absorbed in undepleted material on either side of the junction, allowing either electrons or holes to diffuse into the field region. This method has been employed successfully to determine ionization rates in other III-V materials. ${ }^{12,13}$ Earlier measurements of the ionization rates in InP have been reported ${ }^{14}$ for diffused junction devices where the photomultiplication data were interpreted under the invalid assumption that $\alpha=\beta$. Measurements have also been reported ${ }^{15}$ on InP Schottky-barrier diodes, a configuration for which the interpretation of the data is subject to several uncertainties, ${ }^{16}$ with the result $\beta / \alpha \approx 5$.

The avalanche photodiodes used here were of the inverted-mesa geometry, analogous to that used for the previously described GalnAsP/InP devices. ${ }^{17}$ They were fabricated by etching $138-\mu \mathrm{m}$-diam mesas in a wafer consisting of a 5- $\mu \mathrm{m}$-thick $\mathrm{n}$-InP layer $\left(\mathrm{n}=1.7 \times 10^{16} \mathrm{~cm}^{-3}\right)$ grown by LPE on a (100)-oriented $\mathrm{p}^{+}-\operatorname{InP}(\mathrm{Zn})$ substrate $\left(\mathrm{p} \approx 2 \times 10^{18} \mathrm{~cm}^{-3}\right)$. Mesas were etched using a 1:1 mixture of $3 \% \mathrm{Br}$-methanol: $\mathrm{H}_{3} \mathrm{PO}_{4}$ at $45^{\circ} \mathrm{C}$. Ohmic n- and p-type contacts were made by microalloying plated AuSn and evaporated AuMg, respectively. The center portion of the substrate was thinned to within $4 \mu \mathrm{m}$ of the junction, using a jet of a 1:1:6:1 mixture of $\mathrm{HAc}: \mathrm{HClO}_{4}: \mathrm{HNO}_{3}: \mathrm{HCl}$, to facilitate photoinjection of electrons. ${ }^{\dagger}$ The final device structure is shown in the inset in Fig. II-6. The etched moat around the base of the mesa is an artifact of the etching procedure and has the positive attribute of insuring electrical isolation of the mesa while retaining some additional physical support in the rest of the wafer.

Dark currents of the diodes were subnanoampere up to voltages very close to breakdown. Figure II- 6 illustrates the I-V characteristic of a typical diode. For some of the better devices, uniform photoresponse gains (within \pm 10 percent) of about 12 were measured with leakage currents as low as $0.35 \mathrm{nA}$. Typically, however, leakage currents at this value of gain tended to be about an order-of-magnitude larger. Reasonably uniform photoresponse gains of 150 with a concurrent leakage of $120 \mathrm{nA}$ have been measured. Capacitance-voltage data indicated that these devices were abrupt-junction diodes. Scanned photoresponse measurements from both sides of the wafer using the $6328-\AA$ line of a HeNe laser were performed to ensure the absence of microplasmas and edge breakdown in the devices chosen for study. The diodes selected for photomultiplication measurements had uniform multiplication ( \pm 10 percent) over the area of the diode for the range of voltages used in the experiment.

† The electron-diffusion length in $\mathrm{p}^{+}-\mathrm{InP}$ and the hole-diffusion length in $\mathrm{n}$-InP were estimated from electron-beam-induced current measurements on similar diodes to be approximately 1.4 and $2.8 \mu \mathrm{m}$, respectively. 
Photonutiptication measurements were performed using a focused beam of $6328-\AA$ radiation, incident alternately on the $\mathrm{n}$ and $\mathrm{p}^{+}$sides of the diodes. The large value of the optical absorption coefficient in $\ln P$ at this wavelength $\left(\alpha \sim 5 \times 10^{4} \mathrm{~cm}^{-1}\right)$ (see Ref. 18) guarantees that essentially all the incident light is absorbed outside of the depletion region, resulting in pure (less than 1 part in $10^{3}$ contamination) hole and electron injection, respectively. The photoresponse as a function of reverse bias for each case was monitored with a lock-in amplifier. The injected photocurrent was of the order of $5 \mathrm{nA}$. Over a rather wide range of increasing reverse bias, below that at which multiplication was evident, the photocurrent rose slowly and very nearly linearly due to the increased collection efficiency of the widening depletion region. A linear extrapolation of this low-field photoresponse was subtracted out at the higher fields to yield the values of the hole-initiated $\left(M_{p}\right)$ and electron-initiated $\left(M_{n}\right)$ multiplication shown in Fig. 11-7. The ionization rates were determined as a function of peak electric field $\left(E_{m}\right)$ from the multiplication data by means of the following equations which apply for the case of a one-sided, abruptjunction device with pure-electron and pure-hole injection, respectively: $!^{19}$

$$
\begin{aligned}
& \alpha\left(E_{m}\right)=\beta\left(E_{m}\right)+E_{m} \frac{d}{d V}\left[\ln \left(\frac{M_{n}}{M_{p}}\right)\right] \\
& \beta\left(E_{m}\right)=\frac{E_{m}}{M_{n}} \frac{d}{d V}\left(\ln M_{p}\right)
\end{aligned}
$$

$\mathrm{E}_{\mathrm{m}}$ was calculated using the applied voltage (V) and the carrier concentration obtained from capacitance-voltage measurements.

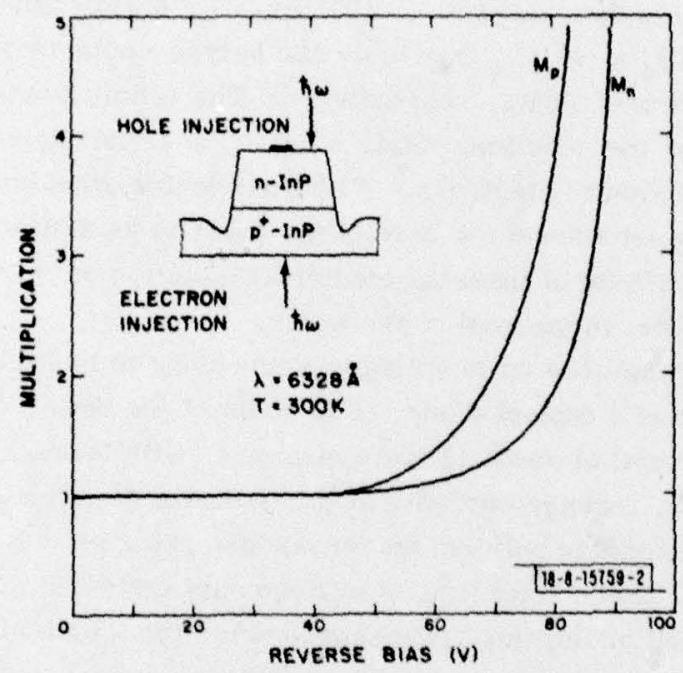

Fig. II-7. Electron-initiated $\left(\mathrm{M}_{n}\right)$ and hole-initiated $\left(M_{p}\right)$ avalanche multiplication as a function of reverse bias in InP. Inset shows schematic diagram of experimental configuration.

Application of Eqs. (II-1) and (II-2) to the multiplication data of Fig. II-7 yields the hole- and electron-ionization rates, plotted in Fig. II-8 as a function of $1 / \mathrm{E}_{\mathrm{m}}$. These results show clearly that the ionization rate for holes is greater than that for electrons over the entire range of electric-field strengths considered. For a peak electric-field strength of $4.85 \times 10^{5} \mathrm{~V}-\mathrm{cm}^{-1}$, the ratio of hole-ionization rate to electron-ionization rate $(\beta / \alpha)$ is 3.8. This ratio decreases with increasing electric field until $\beta / \alpha=2.7$ at $\mathrm{E}_{\mathrm{m}}=6.37 \times 10^{5} \mathrm{~V}-\mathrm{cm}^{-1}$. A least-squares fit 


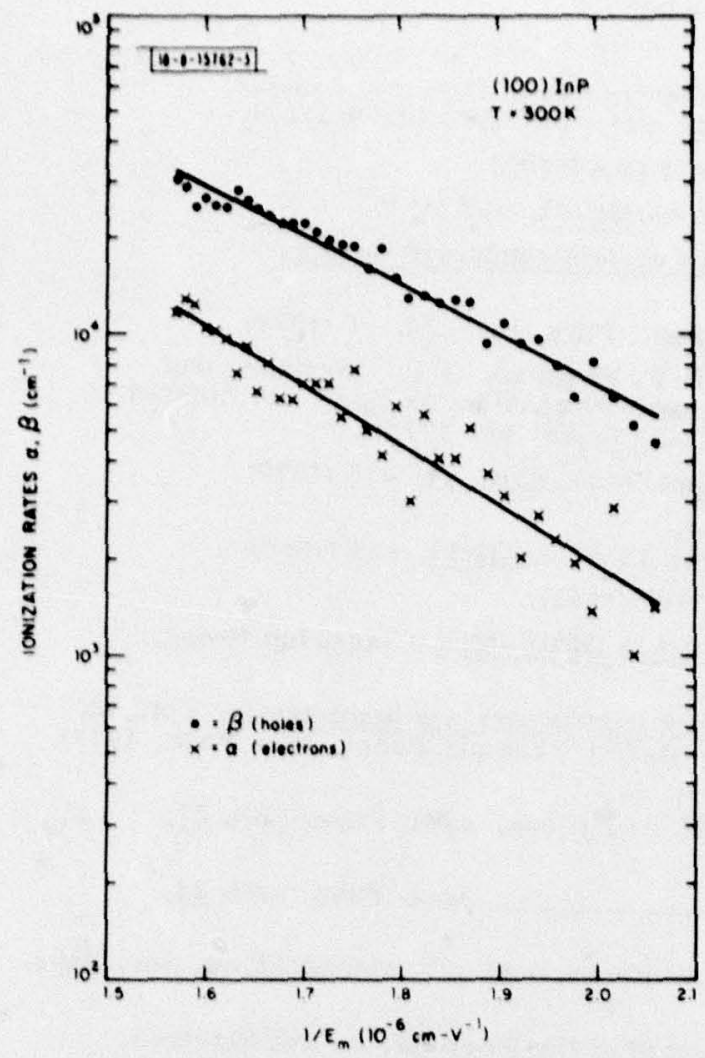

Fig. II-8, Ionization rates of electrons and holes in InP as a function of reciprocal peak electric field.

of these data indicates that the ionization rates can be approximated over the range of electric fields used in this experiment as

$$
\begin{aligned}
& \alpha(E)=1.07 \times 10^{7} \exp \left[-4.31 \times 10^{6} / E\right] \\
& \beta(E)=9.63 \times 10^{6} \exp \left[-3.61 \times 10^{6} / E\right] .
\end{aligned}
$$

It is known from recent measurements in GaAs that the ionization coefficients can be sensitive functions not only of electric field but of crystal orientation as well. ${ }^{20}$ To fully characterize avalanche multiplication in InP, measurements over a wider range of electric fields are required on diodes with different crystal orientations, and such studies are presently under way. The measurements described in this report do provide some initial values for the ionization rates in (100)-InP, results which should be reliable because of the unambiguous nature of the experimental technique employed. In addition, it has been demonstrated that uniform, high-gain, lowleakage avalanche photodiodes, suitable for use as detectors as well as for multiplication measurements, can be fabricated.

Extension of these studies to the GalnAsP system to obtain data necessary for the optimization of avalanche photodiode structures useful at longer wavelengths is straightforward. In fact, it should actually be easier in view of the fact that the InP substrate and cap layer in the latter devices is transparent to the exciting radiation, and hence no thinning is required.

C. A. Armiento

S. H. Groves

C. E. Hurwitz 


\section{REFERENCES}

1. Semiannual Technical Summary on Electrooptical Devices, Lincoln Laboratory. M.I.T. (31 March 1978), p. 1, DDC AD-A059062/0.

2. Ibid. (30 September 1978), p. 1, DDC AD-A069091.

3. T. L. Paoli, IEEE J. Quantum Electron. QE-13, 351 (1977).

4. See, for example, S. M. Sze, Physics of Semiconductor Devices (Wiley, New York, 1969), p, 122 .

5. J. P. Donnelly and C. A. Armiento, Appl. Phys. Lett. 34, 96 (1979).

6. W. T. Devlin, K. T. Ip, D. P. Leta, L. F. Eastman, G. H. Morrison, and J. Comas, presented at 7 th International Symposium on GaAs and Related Compounds, St. Louis, Missouri, 24-27 September 1978.

7. J. P. Donnelly and C. E. Hurwitz, Appl. Phys. Lett. 31, 418 (1977), DDC AD-A050856/4.

8. R. J. McIntyre, IEEE Trans. Electron Devices ED-13, 164 (1966).

9. R. B. Emmons, J. Appl. Phys. 38, 3705 (1967).

10. G. Gibbons, Avalanche-Diode Microwave Oscillators (Clarendon Press, Oxford, 1973), pp. 66-72.

11. G. E. Stillman and C. M. Wolfe, in Semiconductors and Semimetals, Vol. 12, edited by R. K. Willardson and A. C. Beer (Academic Press, New York, 1977). p. 330 .

12. T. P. Pearsall, R. E. Nahory, and M. A. Pollack, Appl. Phys. Lett. 27, 330 (1975).

13. $403(1976)$. Appl. Phys. Lett. 28,

14. I, P. Molodyan, S. I. Rodautsan, E. V. Russu, and S. V. Slobodchikov, Sov. Phys. Semicond. 8,879 (1975).

15. C.W. Kao and C.R. Crowell, presented at the Workshop on Hot Electron Phenomena in Semiconductors, Cornell University, 17-19 August 1978 (unpublished).

16. G. E. Stillman and C. M. Wolfe, loc. cit., p. 347.

17. Semiannual Technical Summaries on Electrooptical Devices, Lincoln Laboratory, M.I. T. (30 September 1977), p. 7, DDC AD-A054477/5; and (31 March 1978), p. 3, DDC AD-A059062\%.

18. B. O. Seraphin and H. E. Bennett, in Semimetals and Semiconductors, Vol. 3, edited by R. K. Willardson and A. C. Beer (Academic Press, New York, 1967), p. 527.

19. M. H. Woods, W. C. Johnson, and M. A. Lampert, Solid-State Electron. 16. 381 (1973).

20. T. P. Pearsall, F. Capasso, R. E. Nahory, M. A. Pollack, and J. R. Chellkowsky, Solid-State Electron. 21, 297 (1978). 
UNCLASSIFIED

SECURITY CL ASSIFICATION OF THIS PAGE (WhEn Data Entered)

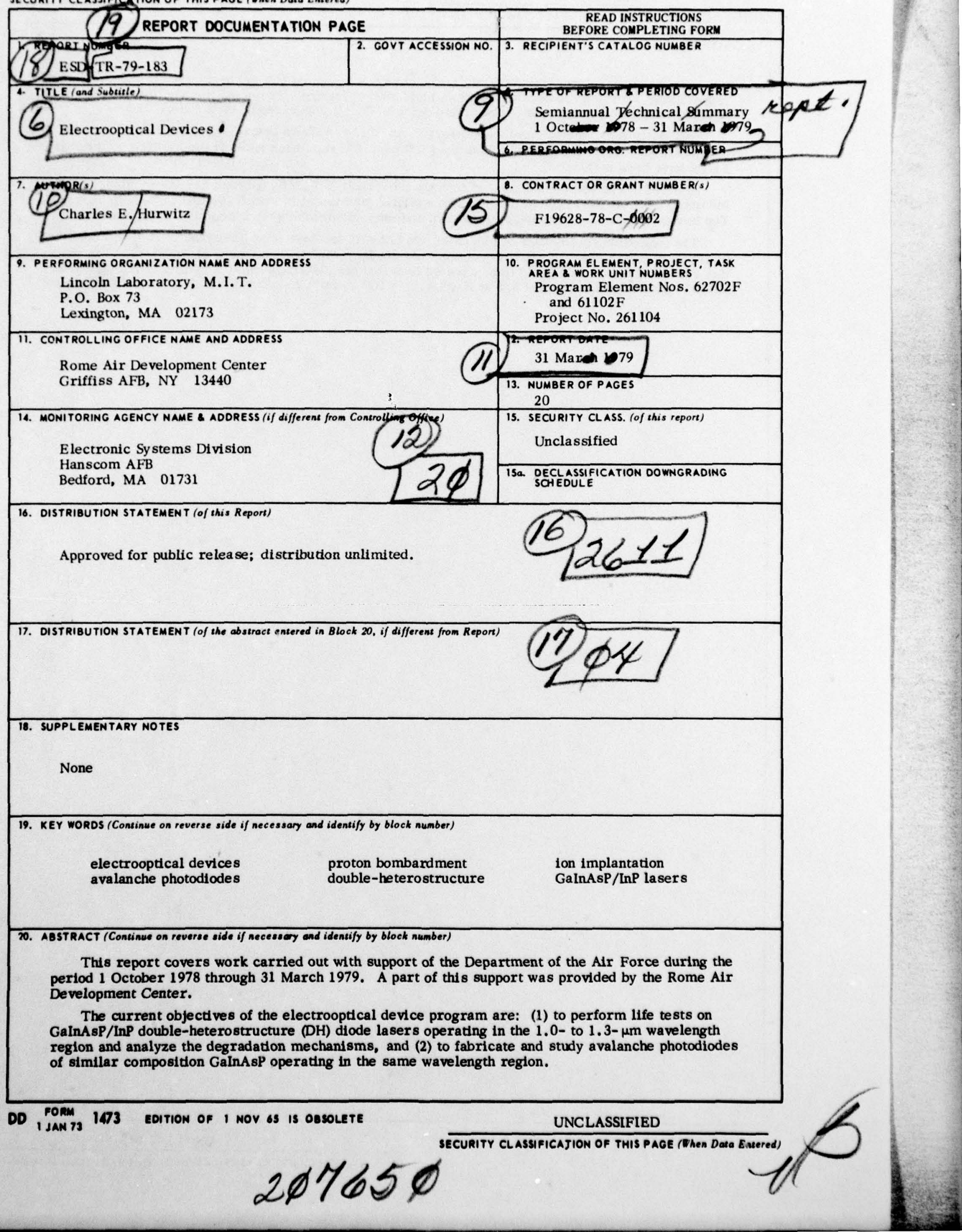


SECURITY CLASSIFICATION OF THIS PACE (Whea Data Bniered)

20. ABSTRACT (Contiatued)

Two stripe-geometry GaInAsP/InP lasers have now operated CW for nearly 8,000 and 10,000 hr, respectively, at room temperature with no indication of fallure. Projected lifetime for CW operation at room temperature, based on accelerated aging at $50^{\circ} \mathrm{C}$, now exceeds $15,000 \mathrm{hr}$.

Self-pulsations, similar to those observed in GaAs/AlGaAs lasers, have been noted in some GaInAsP/InP lasers. Pulse widths less than 100 psec and repetition rates from $100 \mathrm{MHz}$ to more than $1 \mathrm{GHz}$ have been measured.

Guarded avalanche photodiodes of both the $p^{+}-n$ and $n^{+}-p$ configurations have been fabricated in InP using a double fon implantation to form a planar junction with a central uniform thigh-tield region. The devices were free from edge breakdown and showed uniform avalanche gains as high as twenty.

The ionization coefficients of electrons and holes in InP have been determined from photomultiplication measurements on abrupt-junction, low-leakage, $\mathrm{np}^{+}$InP avalanche photodiodes. The ionization rate of holes $(\beta)$ was found to be greater than that for electrons $(\alpha)$, the ratio varying with peak electric field $(\mathrm{Em})$ from $\beta / \alpha=3.8$ at Em $=4.85 \times 10^{5} \mathrm{~V}-\mathrm{cm}^{-1}$ to $\beta / \alpha=2.7$ at $\mathrm{E}_{\mathrm{m}}=6.37 \times 10^{5} \mathrm{~V}-\mathrm{cm}^{-1}$. 